\title{
ПЕРЕСТУПАЯ ЧЕРЕЗ ПОРОГ КИБОРГИЗАЦИИ
}

Гринин А..$^{1}$

Гринин $\Lambda$.Е. ${ }^{2}$

${ }^{1} \mathrm{PhD}$ in Biological Sciences, Moscow State University

${ }^{2} \mathrm{PhD}$, Professor, The Institute of Oriental Studies of the Russian Academy of Sciences (RAS), Moscow,

Vice-Director of the Eurasian Center for Big History \& System Forecasting

With the support of the Russian Science Foundation grant 20-61-46004

Correspondence I Anton Grinin, algrinin@gmail.co; Leonid Grinin, leonid.grinin@gmail.com

Citation I Grinin, Anton and Leonid Grinin. 2020. “ПЕРЕСТУПАЯ ЧЕРЕЗ ПОРОГ КИБОРГИЗАЦИИ”

Journal of Big History 4 (3): 66-78.

DOI I https://doi.org/10.22339.jbh.v4i3.4331

\section{КЛЮЧЕВЫЕ СЛОВА}

Киборгизация,

Большая

История,

колиективное обучение,

Кибернетическая революция.

\section{АННОТАЦИЯ}

Тема киборгов уже давно волнует умы людей. Однако то, что было только предметом фантастических романов и фильмов, уже становится реальностью. Мы живем в удивительное время, когда воочию наблюдаем, как разворачивается киборгизация. Под киборгизацией мы имеем в виду постепенную замену частей человеческого тела раздичными технологичными имплантантами. В настоящей статье мы рассмотрим развитие процесса киборгизации, его предпосылки, а также его место и роль в Большой Истории. Авторов волнует вопрос о том, придет ди когда-нибудь время, когда человек будет в основном иди полностью состоять не из биологического, а из искусственного материла? В статье также затрагиваются и другие проблемы и риски, связанные с будущим научно-техническим прогрессом.

\section{ВВЕДЕНИЕ. КИБОРГИЗАЦИЯ В БОЛЬШОЙ ИСТОРИИ}

Процесс киборгизации

можно рассматривать не только как часть истории медицины, но и как часть технологической эволюции. В целом вся человеческая история, особенно последние несколько веков, - это история триумфа науки и техники. С самого появления Homo sapiens, жизнь древних людей была связана с технологиями (учитывая популярную идею о том, что труд, в основном «производство» каменных орудий труда, превратил обезьян в людей). В результате человечество, создавая новые технологии, становилось все более зависимым от них (Grinin L, Grinin A. 2015, 2016). В наши дни технологии обслуживают практически все аспекты нашей жизни, однако в ближайшем будущем возможны более серьезные преобразования, когда технологии будут самоуправляемыми и смогут слиться с человеческим телом и разумом.

Киборгизация - это процесс замены частей человеческого тела различными технологичными имплантантами. В какой-то степени этот процесс начался очень давно. Самые ранние свидетельства протезирования зарегистрированы в Древнем Египте. Исследователи обнаружили в Каире протез большого пальца ноги, сделанного из дерева и датируемого 950 -710 годами до н. э. (Finch et al. 2012). Еще один старейший протез был найден в гробнице в Капуе (Италия), в 1858 году. Он датируется самнитскими войнами 300 г. до н. э. Протез этот был сделан из меди и дерева (Bennett Wilson 1964). В средние века были довольно распространены протезы из железа, которые изготавливались оружейниками для рыцарей, потерявших конечности в боях (Sellegren 1982). Один из 
самых известных примеров подобных протезов -железная рука немецкого рыцаря, наемника и поэта Гетца фон Бирлихнгена. выполненная в 16 веке, и которая имела весьма сложный механизм для того времени (Goethe n.d.).

Прогресс в области искусственных частей тела рос, и достиг сегодня уже таких пределов, что каждый из нас сегодня может считать себя хотя бы в малой степени киборгом. Без сомнения, у большинства людей на планете есть накладные ногти, искусственные зубы, очки, контактные линзы или искусственные хрусталики. По оценкам Управления по контролю за продуктами и лекарствами США, во всем мире уже 324200 человек имеют слуховые имплантаты (Technavio 2016). В 2016 число носителей слуховых имплантатов составляло уже около 6оо,ооо (The Ear Foundation 2017). Сегодня такие искусственные органы как сердце (DeVries et al. 1984), почки, печень, поджелудочная железа (Stamatialis et al. 2008) становятся реальностью. Разрабатываются бионические глаза (Boyle et al. 2003), бионические конечности (Farina и Aszmann 2014) и многое другое.

К сожалению, несмотря на то, что практическая киборгизация быстро развивается, в литературе обнаруживается явный недостаток теоретических концепций, систематично описывающие это явление и показывающих его происхождение и тренды развития. Среди наиболее популярных теорий стоит выделить трансгуманизм, который был заложен в 1923 годы британским генетиком Дж. Б. С. Холдейном (Haldane 1924; Huxley 2015), а также широко известную теорию Курцвейла (Kurzweil 2010).

На наш взгляд, происхождение и направления развития киборгизации могут быть хорошо поняты в рамках Большой Истории. Киборгизация в ее зрелых чертах может быть рассмотрена как важная веха в Большой Истории, она является пересечением между Человеческой и новой «Постчеловеческой» революциями. Поскольку мы только входим в эру киборгизации, последствия этого процесса пока еще не ясны, но уже очевидно, что "Постчеловеческая" революция будет периодом интенсивного воздействия на организм человека. На наш взгляд, основы киборгизации уже проявилось в коллективном обучении, которое начинается с шестого этапа Большой Истории. Коллективное обучение - термин, введенный Дэвидом Кристианом (см. например Christian 2012; 2018) Под ним понимается развитая система общения и обмена информацией в таком объеме и с такой точностью, что новые информация накапливается на уровне сообщества и даже вида (Christian 2015). Коллективное обучение стало основой развития технологий и обеспечило переход на новые рубежи Большой Истории: «Сельское хозяйство» и «Современная революция » (David Christian et al. 2014; Spier 2015). На наш взгляд, коллективное обучение будет развиваться в глобальной системе обмена информацией между человеческим мозгом и компьютерными интерфейсами. Процесс совмещения человеческого мышления с технологиями станет важным этапом киборгизации и даст импульс для дальнейшего развития Большой Истории. Возможно, это даже положит начало новому виду эволюции. Как писал Р. Докинз, «всякий раз, когда возникают условия, в которых новый тип репликатора может создавать копии самого себя, такие репликаторы стремятся взять верх и основать новый вид собственной эволюции» (Dawkins 2006)

\section{КИБЕРНЕТИЧЕСКАЯ РЕВОЛЮЦИЯ}

Как мы уже отметили, сегодня мы стоим на пороге Постчеловеческой революции. Возможно, и даже скорее всего, она будет менее радикальная, чем представляют себе трансгуманисты и другие последователи практического бессмертия. Однако, в любом случае она значительно увеличит продолжительность жизни, приведет к технологиям выращивания биологических искусственных тканей и органов и замены ими или их небиологическими аналогами 
вышедших из строя естественных оргакнов, интеграции мозга с электронными устройствами и др.

В 1950 и 196о годах мир (в первую очередь, развитые страны) стал свидетелем крупнейшей технологической революции, которая продолжается и по сей день. В конце 20-го века, достижения этой революции, особенно в области информационных технологий распространились по всему миру. Мы называем ее Кибернетической революцией (Grinin L. и Grinin A. 2015, 2016), поскольку наука кибернетика изучает информацию и ее преобразования в различных сложных системах. Кибернетическая революция на первом этапе (с 1950-х до наших дней) радикально изменила процессы обработку информации, а также обеспечила прорыв в регулировании сложных процессов в широком спектре естественных и искусственных систем, которые стали частью производственного процесса. (а в будущем он обеспечит прорыв, создав принципиально новую среду саморегулируемых систем).

Кибернетическая революция, стала третьей по величине производственной революцией в человеческой истории после Аграрной и Индустриальной. Мы считаем, что революционные изменения, с которыми мир столкнется в ближайшие 6о-70 лет, произойдут во время второй (заключительной) фазы Кибернетической революции. ${ }^{1}$

Развитие киборгизации в завершающей фазе Кибернетической революции уже сегодня имеет важные предпосылки. В первую очередь, это общая тенденция повышения качества жизни и долголетия. Во-вторых, это тенденция развития различных саморегулируемых систем и технологий (последние мы определяем как способные работать без прямого управления человеком).

Одной из важнейших движущих сил заключительного этапа Кибернетической революция станут медицина, аддитивные, био - и нанотехнологии, робототехника, ИКТ и когнитивные технологии, которые вместе образуют сложную систему саморегулируемого называем этот производства. Мы конвергенцией.

Существует ряд причин, почему медицина станет ядром Кибернетической революции. Во -первых, медицинские услуги быстро растут, составляя около 10 процентов от мирового ВВП (WHO 2020) и они продолжат расти. Вовторых, на периферии страны формируют огромный средний класс, одновременно с сокращением бедности и неграмотности. В результате, акцент сместится в сторону устранения условий мешающих повышению уровня жизни, здравоохранения и т.д.

Другая важная причина - это глобальное старение населения (см. например Vollset et al. 2020). Старение населения скоро будет характерным не только для развитых стран, где это станет критически важным для демократии, а также для Китая, но и для ряда развивающихся, в т.ч. Индии. Во всех странах обострится проблема пенсий (так как количество пенсионеров будет расти) и одновременно увеличится нехватка квалифицированной рабочей силы. Таким образом, многим государствам придется решать проблему нехватки рабочей силы и пенсионных отчислений за счет повышения пенсионного возраста на 10-15 лет. Это также относится и к людям с ограниченными возможностями, поскольку их вовлечение в рабочий процесс будет расти благодаря новым технологиям и достижениям медицины. В то же время рождаемость во многих развивающихся странах странам значительно снизится (Vollset et al. 2020). В целом эти условия предполагают участие государства, а также крупные инвестиции, деловую активность, развитие науки, чтобы обеспечить прорыв в здравоохранении. Рост уровня жизни, образования и среднего класса в развивающихся странах также будет способствовать росту значения медицинских услуг. Формирование таких уникальных условий необходимо для начала новой фазы Кибернетической революции. Этому, скорее всего, также будет способствовать угроза пандемий (что показал COVID-19), требующая 
срочного решения ряда медицинских проблем и дополнительно привлекающая в эту область огромные капиталы и крупные финансовые ресурсы.

\section{ВЕДУЩИЕ ТЕХНОЛОГИИ КИБОРГИЗАЦИИ}

В настоящее время наблюдается значительный рост саморегулируемых и умных технологий в различных отраслях медицины, таких, как системы жизнеобеспечения. Другие же системы только движутся в направлении самоуправления. Например, гибкие управляемые инструменты позволяют докторам оперировать в труднодоступных частях тела с минимальными повреждениями и разрезами. Можно ожидать, что в ближайшем будущем многие операции будут рутинно проводиться роботами без участия людей, (см. например, Fortune Business Insights 2019). Мы полагаем, что самоуправляемые системы будут играть очень важную роль в киборгизации.

Один из ярких примеров самоуправляемых технологий - различные биосенсоры или биочипы. Это относительно молодое направление, представляющее сочетание медицины и нанотехнологий. Биочипы способны регистрировать широкий спектр физиологических изменений и реагировать на них или выполнять определенные действия. В долгосрочной перспективе биочипы позволят постоянно контролировать здоровье человека. В результате постепенного уменьшения размера резистора (Реercy 200о) некоторые биочипы стали настолько малы, что их встраивают в клетки (их часто называют наночипами). Эти миниатюрные биочипы могут использоваться для разных целей, например, для адресной доставки лекарств (Wang et al. 2015). Дальнейшая микроминиатюризация позволит создать систему, которая будет постоянно отслеживать важные параметры тела, фиксировать действия а также отслеживать местонахождения человека. Мы полагаем, что подобные самоуправляемые системы будут очень распространены в завершающей фазе Кибернетической революции.

Другое важное направление самоуправляемых технологий - это нейроинтерфейсы, системы взаимодействия между мозгом и компьютером, которые могут быть реализованы посредством контакта электрода с кожей на голове или посредством электродов, имплантированных в мозг. Сегодня нейроинтерфейсы уже широко используются, особенно в медицине, например, в искусственной визуализации или в бионике. В будущем возможно существенное продвижение в области реабилитации людей с инсультами и травмами головы. Также нейроинтерфейсы станут основой для развития искусственных конечностей, которые будут контролироваться напрямую мозгом. Особенно это будет актуально в ортопедии или бионике, поскольку по данным Организации Здравоохранения, более 1 миллиарда человек имеют тот или иной физический недостаток, и около 190 миллионов взрослых имеют существенную функциональную сложность (The World Bank 2011)..

Важным направлением являются искусственные органы, которые тоже являются сложными самоуправляемыми системами. В настоящее время разработаны и используются уж множество различных искусственных органов: сердце, ухо, глаз, конечности, печень, легкие, поджелудочная железа, мочевой пузырь, яичники, трахея и т. д. (Murphy и Atala 2014; Stamatialis et al. 2008). Более того прогресс искусственных органов также может существенно изменить репродуктивные возможности человека. Так, развитие искусственной матки теоретически может в отдаленном будущем обеспечить возможность иметь детей людям, независимо от пола и возраста (Corea 1986; Rosen 2003).

Безусловно, в действительности киборгизация станет комбинацией применения этих и других технологий. Кроме того, важно отметить, что один и тот же результат может быть достигнут с помощью различных технологий. Например, 
бионический глаз, вероятно, будет реализован как искусственный орган (искусственная копия настоящего). Или же это может быть техническая реализация его функций, например, камера, встроенная в очки, которая фиксирует изображения и передает их на зрительный нерв через нейроинтерфейс (такая технология уже существует, например (Ong и da Cruz 2012)

Говоря киборгизации, нельзя не упомянуть развития роботов. Роботы дойдут до уровня развитых самоуправляемых систем и распространятся во многие сферы нашей жизни. Рынок робототехники, согласно прогнозам, будет расти (Technavio 2020), особенно роботов для медицинской помощи (например, хирургические, как мы упоминали ранее, или роботы для реабилитационной терапии (Burgar et al. 1999).

\section{В ОЖИДАНИИ РАДИКАЛЬНЫХ ПЕРЕМЕН}

Многие исследователи полагают, что мы уже приблизились или приближаемся к довольно серьезным изменениям в разных отношениях, в т.ч. в плане радикального влияния на человеческий организм (а киборгизация является частью этого процесса), и человеческая цивилизация испытает значительные изменения в ближайшие десятилетия. Многие говорят о приближении к точке сингулярности, то есть периоду, в котором прежние тренды развития сильно изменятся. Распространено мнение, что после точки сингулярности начнется новая радикальная фаза развития человечества (здесь следует особо выделить работы Раймонда Курцвейла, например: Kurzweil 2010).

Технологическая сингулярность - это определенный уровень (невиданный ранее) технического прогресса, после которого кривая технологического развития сменится на новый тренд. Мы полагаем, однако, что технологический рост не будет бесконечным. Наш анализ показывает, что есть ряд причин ожидать, что в ближайшие десятилетия, в период когда начнется завершающая фаза
Кибернетической

революции, темпы глобального технологического роста вернутся на некоторое время к гиперболической траектории, (Grinin et al. 202ob)?). Это ускорение будет продолжаться до последних десятилетий 21 века. Согласно нашим расчетам, технологический рост в конце XXI столетия начнет постепенно замедляться до точки сингулярности, которая наступит, ориентировочно в 2106 году (там же). Важно, что глобальный фактор старения будет играть ведущую роль в этом процессе. После точки сингулярности темпы технического прогресса замедлятся по сравнению с предыдущей эпохой, а патерн развития научнотехнического развития резко изменится. Однако в конце двадцать первого века следует ожидать силдьного увеличения возможностей влиять на изменение человеческой природы.

\section{ОТ ЧЕЛОВЕКА К КИБОРГУ ДО КАКОГО ПРЕДЕЛА?}

Сегодня довольно популярна идея трансгуманизма, которая подразумевает возможность киборгизации человека вплоть до изоляции мозга и переноса сознания в абиотическое бессмертное тело. Бессмертие является вообще одной из главных проблем трансгуманизма (Fukuyama 2004; Haldane 1924; Hansell 2011; Huxley 2015; More 2013). Насколько, это действительно возможно? С одной стороны данное направление выглядит довольно логичным, так как медицина шла по этому пути уже многие десятилетия. В наши дни биопринтеры могут создавать различные ткани и органы (Murphy и Atala 2014), нейроинтерфейсы позволяют управлять устройствами "силой мысли" (Schalk et al. 2004). Кроме того, есть своего рода встречное движение технологий в плане сближения людей и искусственных систем, В частности в конструкции человечекоподобных роботов (см. например, Hirose и Ogawa 2007). Поскольку эти роботы будут использоваться не только для работы и развлечений, но и для очень близких или даже интимных контактов с людьми (Yeoman и Mars 2012), границы системы человеческой и искусственной 
антропоморфных систем могут начать растворяться. Не говоря уже о технологиях виртуальной реальности, где даже сейчас становится трудно отличить реальность от иллюзии (Burdea и Coiffet 2003).

Однако, с другой стороны за миллионы лет развития биологическая эволюция сбалансировала все элементы организма и его функции, обеспечив оптимальное и эффективное взаимодействие. Сомнительно, что человеческий мозг может работать без тела, потому что основная цель и функция мозга - это как раз контроль работы организма. Также кажется нерациональным менять все органы, большинство из которых обычно работают нормально. Было бы намного эффективнее и дешевле заменить только вышедшие из строя или менее прочные части. Более вероятно, что процесс из киборгизации никогда не зайдет слишком далеко, и всегда будет «вспомогательным» для биологической составляющей организма, способной значительно улучшить качество жизни и продлить ее.

\section{Сегодня развивается}

возможность создавать искусственные биологические ткани и модели тела с помощью стволовых клеток или других биотехнологий. Мы считаем, что этот путь «починки» нашего организма будет очень перспективным. Для основных жизненно важных органов, таких как сердце, легкие, печень и т. д., он может быть даже более предпочтительным и более эффективным, чем искусственные небиологические органы. Сегодня мы уже знаем случаи, когда человек имел шесть пересадок сердца (и один раз почку) на протяжении жизни. ${ }^{2}$ Сейчас это может себе позволить только очень обеспеченный человек. Однако в будущем это станет возможным для довольно большого количества людей, но не скорее не с помощью трансплантации, а с помощью выращенных в лаборатории органов.

\section{СИСТЕМАТИЗИРУЯ РИСКИ}

Развитие новых технологий обычно начинается с некоторой эйфории от ИХ внедрения, и только гораздо позже приходит понимание проблем, которые технологии приносят, и только после этого принимаются ограничительные меры по снижению некоторых негативных последствий. Возникает вопрос: зачем нам сегодня обсуждать опасности, которые не встретятся в ближайшее время? Однако, дело в том, что будущее может оказаться довольно неожиданным и даже ужасным. И думать об этом нужно заранее. 2020 год показал, что никто не готовился к таким проблемам, как COVID-19, и результат нашей неготовности обошелся миру в десятки триллионов долларов и более, чем один миллион смертей. В этом разделе мы скажем не только о рисках, связанных с движением по пути киборгизации, но и о других, которые могут возникнуть в результате научно-технического прогресса, поскольку все направления последнего тесно связаны.

\section{Этические и моральные проблемы}

В связи с появлением искусственных органов и тканей вопрос встает уже в отношении материальной биологической природы, то есть в самом прямом смысле: из какого материала - будет сделан человек будущего - из биологических естественных или хотя бы биологических искусственных материалов, либо это будет уже вовсе небиологическое создание? Как он будет размножаться? Как будут функционировать его мозг и сознание? Любое такое изменение очень глубоко затронет фундаментальные институты человечества, включая мораль и межличностные отношения. В самом деле, что станет с моралью и какова она будет, если речь идет о смене биологической природы? Мораль и человеческие отношения - это не что-то, существующее отдельно от технологий, тем более от человеческой физиологии и - шире - биологической основы. Это результат очень сложной социобиологической эволюции, и без своей материальной биопсихической оболочки мораль в привычном понимании этого слова может исчезнуть. 
Мы предполагаем, что настоящая киборгизация, если она когда-то все же начнется, будет связана с изменением чувств и сознания человека. В этой области уже ведётся работа. Так, например, недавнее исследование представило концептуальную основу для разработки киборгизации на слиянии организма и ИИ (Wu et al. 2016).

Моральная сторона технологического прогресса не является новой проблемой (см. например Bernal et al. 1929; Haldane 1924). Однако с ростом технологического развития мы встречаем более конкретные и более вызывающие исследования по этой теме, такие, например, как влияние этического суждения о решении человека стать киборгом (Pelegrín-Borondo et al. 2020) или даже по этическим вопросам киберживотных (Xu et al. 2020).

Билл Джой в своей работе поднял важную проблему, касающуюся возрастающей зависимости от машин, опасность «перестать думать и решать ситуацию все большей зависимости от машин, когда люди, потеряв возможность практического выбора, начнут принимать все решения машин» (Joy 2000, стр.2). Вероятно, Джой сгущает краски, когда пишет: «В конце концов, может быть достигнута ступень, на которой решения, необходимые для управления системой, будут настолько сложны, что интеллект людей окажется неспособным к их генерации. На этой стадии эффективное управление перейдет к машинам. Люди уже не станут способными даже просто выключить их, потому что будут столь от них зависеть, что выключение оказалось бы равносильным самоубийству» (Там же). Тем не менее опасность попасть в довольно сильную зависимость от технологических систем вовсе не умозрительная. И что тогда в итоге останется от «свободы выбора» человека, совсем неясно. Кроме того, ситуация, когда системы возьмут на себя бо́льшую часть умственной работы людей, вполне может привести к тому, что ум людей будущего станет работать меньше, чем у современного человека, в результате он ослабеет, подобно тому как слабеют мышцы множества наших современников, не имеющих необходимости выполнять физическую работу. Естественно, в помощь интеллекту будут появляться все более удобные и облегчающие работу мысли системы. Включится положительная обратная связь: ум не хочет напрягаться, устройства облегчают его работу, ум ослабляется еще больше. Поэтому неудивительно, если в будущем «умственная гимнастика» (в виде какой-нибудь таблицы умножения) станет пропагандироваться как очень полезное упражнение, так же как сегодня простые физические нагрузки. Таким образом, указанная и возрастающая опасность попасть в зависимость от технологических систем поднимает и важные моральные аспекты.

Еще одна важная моральная проблема - это неприятие или даже сопротивление научнотехническому прогрессу, что имеет давнюю историю. Самый известный пример луддиты, радикальное движение английских текстильных ремесленников и рабочих в первые десятилетия XIX веке, которое разрушала машины в качестве формы протеста (см. например Binfield 2004; Jones 2013). Эта борьба не было вызвана лишь невежеством, но и классовым и интересами, поскольку ткачи ясно понимали, что машины отнимают у них заработок. И это не единственный в истории пример, когда прогресс обострял ситуацию в обществе, приводил к банкротствам, уничтожал многие профессии; иногда он даже приводил к запустению целых городов и территорий, а также часто ухудшал качество жизни. Иногда это открывало неожиданные возможности для злоупотреблений или было источником отчаянной социальной борьбы и угнетения. Тем не менее, замедлить этот процесс никому не удалось. Ужесточение требований к новым лекарствам, запрет ГМО или клонирования, а также многое другое - это современные проявления такой борьбы с технологическим прогрессом. Очевидно, что многие из подобных ограничений и запретов абсолютно необходимы. С одной стороны, трудно ожидать, что можно поставить под полный 
контроль развитие научно-технического прогресса. C другой стороны, достижения, сделанные в процессе борьбы за экологически ориентированное производство или безопасные лекарства показывают, что здесь вполне возможно добиться определенного уровня контроля. В целом минимизация ущерба от инноваций должна осуществляться путем создания определенных институтов и правил, оптимизирующих контроль над технологиями. Но особенно важно делать все это заранее.

\section{Необратимые демографические трансформации.}

Каждая фаза любой производственной революции связан с демографическими ${ }^{3}$ изменениями. Начальная и промежуточная фаза, на которой мы сейчас находимся в Кибернетической революции, создали условия для колоссального роста населения мира. Этот рост происходит в основном в развивающихся странах и во многом является трендом демографической революции индустриальной эпохи. Но с другой стороны, в развитых странах демографическая революция завершилась так называемым демографическим переходом, другими словами - снижением рождаемости. При этом значительно увеличилась продолжительность жизни и еe качество. Демографический переход во многом стал результатом начальной фазы Кибернетической революции (именно на ее первой фазе удалось добиться прорыва в вопросах планирования семьи). Недаром во все большем числе развивающихся стран коэффициенты рождаемости снижаются, в некоторых из них также наблюдается заметное старение населения. Но в процессе той же Кибернетической революции демографическая структура существенно изменилась. Из пирамидальной структуры (когда дети и молодежь составляют основную часть населения) она двигается в сторону превращения этой структуры в прямоугольную, когда количество пожилых людей почти равно количеству молодежи (подробнее о глобальном старении и технологиях прогресса см. L. Grinin et al. 2020). Мало того, в ближайшем десятилетия мы будем наблюдать старение мирового населения, в результате чего его структура приобретет форму обратной пирамиды (когда количество детей и молодых когорт будет меньше, чем у пожилых людей). В некоторых развитых странах

ожидаемая продолжительность жизни может увеличиться до 95-100 лет, и в целом она может достигать уровня наиболее успешных на сегодняшний день стран (например, в Японии), то есть 8о84 года, но может даже быть и выше (Statista 2015; Vollset et al. 2020). Между тем, особенно быстрый рост числа пожилых когорт будет наблюдаться в ближайшие три десятилетия. В результате разделение будет не на первый и третий миры, а на миры старых и молодых наций. Но к этому времени старение населения будет заметно в большинстве стран мира (возможно, за исключением африканских государств). В то же время замедление темпов рождаемости и исчерпание демографических дивидендов в большинстве стран третьего мира приведет к тому, что демографическая структура существенно изменится, и доля детей и молодежи уменьшится, а доля пожилых людей увеличится. Сказанное о текущих и будущих демографических процессах имеет важное значение и для будущих трендов развития, и для киборгизации в частности, поскольку сокращение доли молодого населения и одновременное увеличение доли пожилого поставят перед обществом проблемы замены выпадающих трудовых ресурсов и обеспечения качество длительной биологической жизни людей $80+$ и 90+. И все это будет решаться за счет технологий и связанных с киборгизацией среди них..

\section{Упадок демократии и борьба поколений}

Старение населения может привести к упадку демократической системы. Демократия может превратиться в геронтократию, из которой будет уже трудно выбраться (Berry 2012; Тере и Vanhuysse 2009). Кризис демократического управления еще 
более вероятен в контексте борьбы за голоса. С увеличением продолжительности жизни и сокращением доли молодежи в структуре населения количество и роль пожилых и старых людей неизбежно возрастут. Вероятны также и изменения в половой пропорции. Кроме того, поскольку пожилое поколение более консервативно в своих предпочтениях и привычках, оно может влиять на выбор политического курса, а также социальные и экономические вопросы, которые могут поставить в невыгодное положение молодое и среднеевозрастное поколения.

Особую тревогу вызывает тот факт, что рост продолжительности жизни может спровоцировать конфликт между поколениями, поскольку растущее число пожилых людей потребует увеличения трудоспособного возраста и трудоспособности на 10-20 лет и более (наряду с вовлечением нетрудоспособных людей в связи с появлением новых технических средств и достижений медицины). В этом случае старшее поколение, вероятно, будет препятствовать развитию карьеры молодого поколения. Также пожилое население может способствовать растущему консерватизму общества, что может замедлить технологический рост в будущем. Убрать пожилых людей с пути молодежи станет сложной задачей, и на этом пути, как говорил Ф.Фукуяма,нам, возможно, в конечном итоге придется найти формы институционального «эйджизма», чтобы позволить молодым людям войти в рабочий процесс в мире с высокой ожидаемой продолжительностью жизни.

Важно отметить, что такой поворот к геронтократии наиболее быстро наметится в странах Европы и США. С одной стороны, эти страны имеют сильнейшие демократические традиции, а с другой стороны, здесь в них наиболее заметен этнокультурный дисбаланс (в будущем в США можно ожидать противостояния молодого латинского и пожилого белого населения, тогда как в Европе это будет между молодым исламским и пожилым белым христианским населением).
Это означает, что разрыв между Севером и Югом может воспроизводиться в любой другой стране, где пожилые коренные нации будут жить бок о бок с гораздо более молодым населением, имеющие различные культурные традиции. Конфликты между поколениями в этих странах, вызванные описанным выше кризисом демократии, неизбежно повлияют на судьбу всего мира в условиях глобализации.

\section{Геополитика искусственного воспроизводства}

В конце прошлого века стало ясно, что возможность влиять на геном и систему воспроизводства человека может породить множество сложных социальных, политических, этических и юридических проблем в будущем. Тем не менее, модификация человеческих эмбрионов уже началась и идет полным ходом. Например, в 2015 году Китай заявил о проводимых работах по модификации человеческого эмбриона (Cohen 2019), а несколько позже об этом заявили и в Россияи (Суranoski 2019). Если такие исследования, a также методы выращивания детей вне материнской плаценты будут развиваться, структура воспроизводства населения кардинально изменится. Помимо отношения к вопросу о разрыву связей между поколениями эта проблема имеет и глобальный аспект. Будут ли страны и мир в целом готовы к таким изменениям? И не захотят ли некоторые страны извлечь выгоду из своих демографических преимуществ (что было бы вполне естественным ходом вещей)? Тут открывается простор для фантазии. С одной стороны, очевидно, что в будущем при создании каких-то международных структур и выработке квот для разных государств численность населения страны станет намного важнее, чем сегодня (в наши дни статус страны скорее измеряется его богатством и военной мощью). Но согласится ли Запад с тем, что страны с гораздо большим населением будут диктовать свои условия? 
С другой стороны, почему бы некоторым политическим элитам не использовать новые репродуктивные технологии и, например, не стартовать новую гонку в приросте населения.

\section{ЗАКЛЮЧЕНИЕ. МЕЖДУ}

\section{ТЕХНОЛОГИЧЕСКИМ ОПТИМИЗМОМ И} РАЗУМНОЙ ОСТОРОЖНОСТЬЮ

Чем быстрее происходят изменения, тем сложнее обществу следовать за ними и тем более неоднородным оно становится в социальном (а часто и этнокультурном) плане. Кибернетическая революция привела к взрывному росту информации. Это затрудняет для многих людей освоение новых технологий и серьезно разделяет общество. «Молодые люди считают себя «цифровыми аборигенами» и снисходительно смотрят на «цифровых иммигрантов», пожилых людей, выросших с книгами, ручками и бумагой», писали президенты Римского клуба (von Weizsäcker и Wijkman 2018, р.46) В некотором смысле технический прогресс ускоряется за счет возрастающей необходимости адаптироваться и учиться, и, следовательно, все больше и больше полагаться на технологии. Это формирует новое коллективное обучение, которое будет сочетанием человеческого опыта и технологических возможностей, и даст импульс для будущего этапа развития Большой Истории после преодоления 9-го рубежа (трешхолда).

Сила человека увеличивается с ростом технологий, но вместе с этим возникает много ранее неизвестных проблем. Поэтому, если мы хотим воспользоваться новыми возможностями (а почему бы и нет?), необходимо предвидеть проблемы и минимизировать их последствия и «шок будущего. ${ }^{4}$ К сожалению, человечество не всегда учится на собственных ошибках и мало обращает внимания на будущие проблемы. Кроме того, довольно трудно предвидеть проблемы. Вот почему нам нужны определенные институты или административно-правовые системы, которые взяли бы технологическое развитие под контроль и развивались бы в сотрудничестве с технологиями, сохраняя при этом их функциональность. Однако для этого необходимо регулировать темпы научнотехнического прогресса в мире. Мы верим, что рано или поздно это станет возможным. К сожалению, пока это недостижимо, поскольку конкуренция между странами в первую очередь основана на разном уровне экономического роста. Становится очевидным, что контроль над опасными изменениями также потребует определенных политических преобразований, которые могут стать чрезвычайно сложными и чувствительными (L. Grinin и Korotayev 2013)?

Между тем в обществе с давнего времени и до сих пор действовали два главных регулятора, без которых оно не может существовать. Это мораль и право, которые также опираются на психологические структуры общества и населения, действующие на почти подсознательном уровне (L. Grinin и Grinin 2016). Но чем быстрее развиваются технологии, тем менее признана мораль, поскольку она не может найти свой новый баланс. Также вполне возможно, что за определенным пределом скорости научно-технического развития может начаться заметное разрушение морали (или ее распад на разные виды морали). И это тем более опасно, когда развиваются мощные технологические возможности трансформации человеческого организма. Изза отсутствия моральных ограничений и стремления к большой прибыли могут преобладать различные опасные явления: от моды на коррекцию тела до попыток стать сверхчеловеческим с помощью новых медицинских технологий.

Юридическое право, появившись в аграрноремесленных обществах, обрело зрелость в период индустриализма (но нормотворчество имеет место в любом обществе). Право, будучи более гибким, чем мораль, тем не менее требует определенной устойчивости, которой, как мы видим, сложно добиться в условиях быстрой смены технологий. По словам С. Лема: перед технологическими 
инновациями общество и его правовые нормы чаще всего оказываются практически бессильными, если только они не вступают в откровенно прямой конфликт с законами» (Lem 1968, стр. 269). И, как справедливо отмечает Лем, интенсивность, с которой «упрощающие дело» технические средства подрывают ценности, имеет положительную корреляцию с их эффективностью. Это значит, что чем эффективнее технологии решают какие-то частные проблемы, тем сильнее они изменяют общество, его морально-правовую ткань, последствия чего начинают осознаваться гораздо позже.

Как будет самоорганизовываться будущее общество в таком случае, неясно. В предшествующие эпохи мораль и право можно было сравнить с двумя ногами, на которых общество стояло довольно крепко (причем там, где был перекос, например право было недостаточно развитым, чувствовался и крен общества). Но, образно говоря, если одна «нога» (мораль) исчезнет, а другая (право) ослабеет, устоит ли общество на такой слабой опоре при столь высокой скорости движения вперед?

Трудно и фактически бессмысленно пытаться помешать прогрессу. Всегда возникает вопрос о том, что считать прогрессом в каждую конкретную эпоху и каковы издержки? В любом случае лучше не торопиться с изменениями с неопределенными последствиями. Ступая на новую землю, лучше быть осторожным, чем торопиться. Наука, инновации и изменения слишком быстро ставят много новых правовых, моральных и экономических проблем и вызывают острые споры, конфликты, торговые войны и фобии. Общественное сознание однозначно отстает. Неконтролируемый технологический прогресс можно сравнить с Роком, легендарной птицей из Арабских ночей, которая быстро несет человечество, но при этом требует человеческих жертв. Готовы ли мы к этому? И чем мы готовы пожертвовать ради прогресса? Эти вопросы - должны стать одними из самых важных при оценке

нашего будущего. И тем более они важны на пути к киборгизации человека.

\section{References}

Bernal, J. D., A. Maurois, and S. Radhakrishnan. 1929. The World, the Flesh and the Devil. London: Kegan Paul, Trench, Trubner.

Berry, Craig. 2012. The Rise of Gerontocracy? Addressing the Intergenerational Democratic Deficit. UK: Intergenerational Foundation.

Binfield, K. 2004. Writings of the Luddites. Baltimore: JHU Press.

Boyle, J., A. Maeder, and W. Boles. 2003. "Scene Specific Imaging for Bionic Vision Implants." In Proceedings of the 3rd International Symposium on Image and Signal Processing and Analysis, 2003. ISPA 2003. (1): 423-427. Presented at the 3rd International Symposium on

Grinin, L., and A. L. Grinin. 2015. “Global Technological Perspectives in the Light of Cybernetic Revolution and Theory of Long Cycles." Journal of Globalization Studies, 6 (2).

Grinin, L., and A. L. Grinin. 2016. The Cybernetic Revolution and the Forthcoming Epoch of Selfregulating Systems. Moscow: Uchitel Publishing House.

Grinin, L., and A. Korotayev. 2013. "Globalization and the World System Evolution." Evolution: Development within Big History, Evolutionary and World-system Paradigms. Yearbook, 30-68.

Grinin, L. E., A. L. Grinin, and A. Korotayev. 2016. "Forthcoming Kondratieff Wave, Cybernetic Revolution, and Global Ageing. Technological Forecasting and Social Change. https://doi.org/10.1016/j.techfore.2016.09.017.

Haldane, J. B. S. 1924. Daedalus or Science and the Future. New York: E P Dutton.

Hansell, G. R. and W. Grassle. 2011. H+/-: Transhumanism and Its Critics. Bloomington, IN: Xlibris Corporation. 
Hirose, M., and K. Ogawa. 2007. "Honda Humanoid Robots Development." Philosophical Transactions of the Royal Society A: Mathematical, Physical and Engineering Sciences, 365 (1850): 11-19. https://doi.org/10.1098/ rsta.2006.1917.

Huxley, J. 2015. "Transhumanism." Ethics in Progress, 6 (1): 12-16.

Jones, S. E. 2013. Against Technology: From the Luddites to Neo-Luddism. New York: Routledge.

Joy, B. 2000. “Why the Future Doesn't Need Us." Wired, April 1, 2000. https:// www.wired.com/2000/04/joy-2/. Accessed October 8, 2020.

Kurzweil, R. 2010. The Singularity is Near. London: Gerald Duckworth \& Co.

Lem, S. 1968. Summa Tekhnologii. Kraków: Wydawnictwo Literackie.

More, M. 2013. "The Philosophy of Transhumanism." The Transhumanist Reader, 8.

Murphy, S. V. and A. Atala. 2014. 3D Bioprinting of Tissues and Organs. Nature Biotechnology, 32 (8): 773-785. https://doi.org/10.1038/ nbt.2958.

Ong, J. M., and L. da Cruz. 2012. “The Bionic Eye: A Review." Clinical and Experimental Ophthalmology, 40 (1): 6-17. https:// doi.org/10.1111/j.1442-9071.2011.02590.

Peercy, P. S. P. 2000. “The Drive to Miniaturization." Nature 406 (6799): 1023-6. https:// doi.org/10.1038/35023223.

Pelegrín-Borondo, J., M. Arias-Oliva, K. Murata, and M. Souto-Romero. 2020. “Does Ethical Judgment Determine the Decision to Become a Cyborg?: Influence of Ethical Judgment on the Cyborg Market." Journal of Business Ethics, 161 (1): 5-17. https://doi.org/10.1007/s10551018-3970-7.

Rosen, C. 2003. "Why Not Artificial Wombs?" The New Atlantis (3): 67-76.

Schalk, G., D. J. McFarland, T. Hinterberger, N. Birbaumer, and J. R. Wolpaw. 2004. "BCI2000: A General-purpose Brain- computer Interface (BCI) System." IEEE Transactions on Biomedical Engineering 51 (6): 1034-1043. https://doi.org/10.1109/ TBME.2004.827072.

Sellegren, K. R. 1982. "An Early History of Lower Limb Amputations and Prostheses." The Iowa Orthopaedic Journal 2, 13-27.

Spier, F. 2015. Big History and the Future of Humanity. New York: John Wiley \& Sons.

Stamatialis, D. F., B. J. Papenburg, M. Gironés, S. N. M. Bettahalli, S. Schmitmeier, and M. Wessling. 2008. "Medical Applications of Membranes: Drug Delivery, Artificial Organs and Tissue Engineering." Journal of Membrane Science 308 (1-2): 1-34. https:// doi.org/10.1016/j.memsci.2007.09.059

Statista. 2015. "Life Expectancy at Birth Forecast United Kingdom 2013-2060 Statistic." Statista. (May 20). https://www.statista.com/ statistics/478512/life-expectancy-birthforecast-united-kingdom-uk/. Accessed October 9, 2020.

Technavio. 2016. "The Number of Cochlear Implants Shipped Worldwide is Expected to Hit 96,000 by 2020." Technavio. (February 1) https://blog.technavio.com/blog/numbercochlear-implants-shipped-worldwideexpected-hit-96000-2020. Accessed 1 October 2020 .

-. 2020. "Robotic Simulator Market Will Showcase Neutral Impact during 2020-2024 I Growing Need for Robotic Simulation to Boost Market Growth." Technavio. (October 7). https://www.businesswire.com/news/ home/20201007005757/en/Robotic-SimulatorMarket-will-Showcase-Neutral-Impactduring-2020-2024-Growing-Need-for-Robotic -Simulation-to-Boost-Market-GrowthTechnavio. 2020. Accessed 1 October 2020. Tepe, M., and P. Vanhuysse. 2009. "Are Aging OECD Welfare States on the Path to Gerontocracy? Evidence from 18 Democracies, 1980 -2002." Journal of Public Policy, 1-28. 
Vollset, S. E., E. Goren, C.-W. Yuan, J. Cao, A. E. Smith, T. Hsiao, et al. 2020. "Fertility, Mortality, Migration, and Population Scenarios for 195 Countries and Territories from 2017 to 2100: A Forecasting Analysis for the Global Burden of Disease Study." The Lancet. https:// doi.org/10.1016/S0140-6736(20)30677-2.

von Weizsäcker, E. U., and A. Wijkman. 2018.

Come on!: Capitalism, Short-termism, Population and the Destruction of the Planet. Springer. Semantic Scholar. Allen Institute for AI.

Wang, X., Z. Mei, Y. Wang, and L. Tang. 2015. "Gold Nanorod Biochip Functionalization by Antibody Thiolation." Talanta 136, 1-8. https://doi.org/10.1016/j.talanta.2014.11.023.

Wilson, A. Bennett. 1964. "Limb Prosthetics Today." Physical Therapy, 44 (6): 435-469. https:// doi.org/10.1093/ptj/44.6.435.

WHO. 2020. "Current Health Expenditure as a Percentage of Gross Domestic Product (GDP)." WHO. (October 6) World Health Organization. http://www.who.int/gho/ health_financing/health_expenditure/en/. Accessed 6 October 2020.

World Bank. 2011. “New World Report Shows More than 1 Billion People with Disabilities Face Substantial Barriers in Their Daily Lives." WHO (June).

Wu, Z., Y. Zhou, Z. Shi, C. Zhang, G. Li, X. Zheng, et al. 2016. "Cyborg Intelligence: Recent Progress and Future Directions." IEEE Intelligent Systems 31 (6), 44-50. https:// doi.org/10.1109/MIS.2016.105

Xu, N., O. Lenczewska, S. Wieten, C. Federico, and J. Dabiri. 2020. "Ethics of Biohybrid Robotic Jellyfish Modification and Invertebrate Research." https://doi.org/10.20944/ preprints202010.0008.v1.

Yeoman, I., and M. Mars. 2012. "Robots, Men and Sex Tourism." Futures 44 (4), 365-371. https://doi.org/10.1016/j.futures.2011.11.004.

\section{Endnotes}

'Важно отметить, что Кибернетическая революция сама по себе стала продолжением основного тренда производственных революций. В макромасштабе технологический рост увеличивался, по крайней мере, за последние 40,000 иет, хотя и с некоторыми флуктуациями (Grinin, Grinin, Korotayev 2020).

${ }^{2}$ Речь идет об уже умершем мультимиллионере Дэвиде Рокфеллере, перенесшим последнюю операцию по трансплантации сердца в возрасте 99 лет.

зМы выделяем три производственных реводюции: Аграрную, Индустриальную и Кибернетическую.

${ }^{4}$ Мы постоянно сталкиваемся с такими потрясениями, поэтому вопрос, поднятый Элвином Тоффлером в его известном «Шоке будущего» почти полвека назад, попрежнему остается актуальным (Toffler 1970). 